\title{
ENTREVISTA COM TERUKO ODA ${ }^{1}$
}

Teruko Fujino Oda (1945-) é poeta e exerce um papel importante na disseminação do haikai no Brasil. Filha de imigrantes japoneses e sobrinha de Hidekazu Masuda (1911-2008), o Mestre Goga, um dos fundadores do Grêmio Haicai Ipê, desde a infância Teruko Oda viu-se cercada pela natureza onde vivia no interior de São Paulo e pela prática do haikai.

À frente da coordenação do Grêmio Haicai Ipê desde 2012, nesta entrevista inédita concedida em março de 2017, Teruko conta-nos sobre o seu primeiro contato com o haikai, sobre as atividades desenvolvidas pelo Grêmio Haicai Ipê e suas expectativas para o futuro.

Débora Tavares²: Você é filha de imigrantes japoneses. Em qual região do Brasil você viveu sua infância e como eram o seu cotidiano e o contato com a natureza, na época?

Oda: Nasci num pequeno sítio próximo à estação de trem Lussanvira, um ramal da antiga ferrovia 'Noroeste do Brasil', na região conhecida como Núcleo Tietê, interior do estado de São Paulo.

Sem TV, rádio ou internet, as brincadeiras se restringiam aos folguedos comuns a todas as crianças da época. Brincadeiras de roda, de esconde-esconde, com bolas, bonecas, carrinhos de madeira, bolha de sabão. Raramente tínhamos permissão para ir à casa de vizinhos. Até os meus cinco ou seis anos, meus pais trabalhavam na lavoura, de onde tiravam o sustento. Quando entrei para a escola, meus pais tinham uma granja. Não sei precisar a quantidade de aves que havia em nosso sítio. Mas lembro que eram dois barracões bem amplos onde se criavam as poedeiras. E um outro menor, fechado, onde se mantinham os pintinhos a uma temperatura estável até que pudessem ser soltos na área externa cercada por alambrados.

1 Data da entrevista: 22/03/2017

2 Entrevista realizada por Débora Fernandes Tavares. Professora da Faculdade Messiânica no Curso de Licenciatura em Pedagogia; Mestra em Letras no Programa de Língua, Literatura e Cultura Japonesa da Faculdade de Filosofia, Letras e Ciências Humanas da Universidade de São Paulo (USP), São Paulo, Brasil, deborafernandestavares@gmail.com_ORCID iD: https://orcid.org/0000-0002-2095-7227). 
Durante o período letivo, não havia muito tempo para brincar, pois a escola ficava a mais de $2 \mathrm{~km}$ de distância. Caminhávamos cerca de uma hora para ir e outra hora para voltar, todos os dias, independente do sol ou da chuva. Pelo caminho, os colegas que moravam ao longo da estrada iam se juntando e chegávamos aos bandos. Todos levavam marmita, pois ficávamos na escola o dia todo.

Em casa, ao fim do dia, ajudava a cuidar dos irmãos menores em companhia de meu pai. Depois do banho, e do jantar, todos que já iam para a escola faziam a lição de casa à luz dos lampiões de querosene. Papai ficava com os irmãos menores e mamãe nos ajudava com a tarefa.

O contato com a natureza era diário: só abrir a porta. Ao redor da casa, havia uma larga faixa de terra que devia estar sempre limpa e com a grama bem podada. Meu pai dizia que era para poder ver as cobras, os lagartos e outros animais silvestres que se aproximassem da casa.

Após essa faixa, havia as plantações de milho, mandioca, feijão e café, e o bosque onde pássaros se abrigavam e de onde os vaga-lumes surgiam às dezenas iluminando a escuridão. Era um espetáculo mágico. Paineiras, ipês e primaveras cresciam livremente em meio às laranjeiras, mangueiras, mamoeiros, abacateiros, limoeiros. Não muito distante, havia uma horta que era cuidada por meu avô. Podíamos brincar livremente pelo sítio e posso afirmar que eu fui uma criança feliz.

DT: Como era o trabalho de seus pais?

Oda: Nessa época, meu pai tinha uma granja e os mais velhos ajudavam a recolher os ovos, selecionar e embalar em caixotes devidamente identificados. Esses caixotes eram deixados junto à porteira do sítio sobre um banco de pedra. $\mathrm{O}$ caminhão da cooperativa passava duas ou três vezes por semana para recolher. Minha mãe estava sempre atarefada, cozinhando, lavando, passando, cuidando da casa e dos pequenos.

DT: Como e quando você conheceu o haikai?

Oda: Não sei precisar a idade, mas acredito que deve ter sido entre 9 e 10 anos, pois ainda morávamos no sítio. Aos 11 anos eu já morava na cidade de Araçatuba. Conheci o haicai, ou o haiku, por mera curiosidade, quando ouvi meu pai tecendo comentários sobre seu haiku que fora selecionado pelo mestre Nenpuku Sato.

DT: Quando começou a escrever haikai? Em português ou japonês?

Oda: Comecei a escrever haicais em português, de forma sistemática, orientada por mestre Goga, em 1988. Goga levava meus haicais para apreciação nas reuniões do recém fundado Grêmio Haicai Ipê. Em 1989 passei a frequentar as reuniões mensais do Ipê. 
DT: Consta em seu livro "Furusato no Uta" (Canção da Terra Natal) que seu pai era discípulo de Nenpuku Sato. Eles costumavam encontrar-se? Conte-nos um pouco sobre isto.

Oda: Sim, meu pai foi discípulo de Nenpuku Sato. À época, década de 50, não havia na vila associações ou clubes onde os interessados pudessem se reunir. Então, os encontros eram realizados nas casas oferecidas pelos praticantes. Acredito que os encontros entre meu pai e o mestre se restringiam a essas ocasiões, pois Sato mantinha reuniões em outras localidades.

DT: Havia na época reuniões para a composição de haikai em sua casa?

Oda: Sim, muitas dessas reuniões foram realizadas em casa, ocasião em que ajudava minha mãe a servir o chá e os doces caseiros.

DT: Com que frequência e que orientações recebia de seu mestre Masuda Goga?

Oda: Não havia uma frequência definida, pois eu tinha emprego fixo e mestre Goga também tinha seus compromissos. As orientações eram passadas informalmente por meio de longas conversas, leitura de textos, pesquisa em livros diversos, geralmente aos finais de semana. Não havia, à época, nenhuma obra em língua portuguesa sobre regras de composição do haicai. Em 1994, em coautoria com Francisco Handa, enfeixamos seus ensinamentos num livreto intitulado 'Introdução ao Haicai'.

DT: Qual a sua atuação profissional na época, além da coordenação do Grêmio Haicai Ipê?

Oda: Trabalhava como coordenadora pedagógica em uma instituição beneficente destinada a crianças carentes, na região de Americanópolis.

DT: Quais os trabalhos relacionados à poesia que você desenvolve hoje?

Oda: Nos últimos anos venho diminuindo minha participação em vários projetos. A doença de meu marido, a chegada dos netos e problemas de saúde me obrigam a repensar a vida e estabelecer prioridades. Quase não tenho feito palestras e oficinas. Atualmente participo como jurada do Concurso de Haicai Prêmio Masuda Goga e do Concurso Literário Yoshio Takemoto, categoria haicai.

Estou responsável pela realização do Concurso Brasileiro de Haicai InfantoJuvenil, evento anual organizado pelo Grêmio Haicai Ipê, destinado a alunos do Ensino Fundamental e Médio de todo o País.

Também respondo pela etapa brasileira do Concurso Mundial de Haicai para Crianças, evento bianual organizado pela JAL Foundation, sede em Tóquio, e patrocinado pela Japan Airlines nos cinco continentes. É um concurso bianual e conta com o apoio da UNICEF. 
Outro grande evento pelo qual estou responsável é o Encontro Brasileiro de Haicai. O primeiro encontro deu-se em 1986 e o último, em 2015. Inicialmente, os encontros eram anuais. Ultimamente, por falta de patrocínio, tem sido a cada dois anos, ou quando temos verba no caixa do grêmio, cuja contribuição é voluntária. Este ano (2017) pretendemos realizar o $26^{\circ}$ Encontro.

DT: Você tem em mente algum novo projeto de livro?

Oda: Sim. Este ano, o Grêmio Haicai Ipê completa 30 anos de atividades ininterruptas. Estamos estudando a possibilidade de publicarmos uma antologia comemorativa.

Também pretendo publicar a segunda edição do catálogo de kigo (termo que faz referência a elementos das estações do ano) intitulado Natureza - Berço do Haicai. A $1^{\text {a }}$ edição, em coautoria com mestre Goga, foi publicada em 1996. Hoje, após 20 anos, pesquisando a utilização dos kigo relacionados na obra, pelos praticantes de todo o país, percebo que muitos verbetes não foram inspiradores ou não fazem muito sentido no nosso contexto. Então, acredito que o novo catálogo terá menos kigo.

Também estou fazendo a revisão do livreto Introdução ao Haicai para publicação da $3^{\text {a }}$ edição.

D.T.: Em que você acredita que a prática de composição de haikais tenha contribuído em sua formação como pessoa?

Oda: Após três décadas de prática, posso afirmar com toda a convicção que sou uma pessoa melhor. Não que a Teruko de 30 anos atrás fosse uma pessoa do mal, mas hoje sou mais zen, mais resignada no sentido de aceitar as próprias limitações e as limitações do outro. Consciente de que somos seres transitórios, aprendemos a viver com mais amor, compaixão e principalmente, gratidão. O haicai nos ensina um jeito de ser e de estar no mundo.

D.T.: Como aconteceu a fundação do Grêmio Haicai Ipê?

Oda: A primeira reunião do Grêmio Ipê aconteceu em 15 de fevereiro de 1987, data considerada como a de sua fundação. Eu comecei a participar das reuniões somente em 1989. Então, o que eu sei sobre o assunto é o que está anotado no site do grêmio. Segundo relato de Francisco Handa, a criação do grêmio Ipê deu-se após a realização do $1^{\circ}$ Encontro Brasileiro de Haicai, em outubro de 1986, patrocinado pela extinta Revista Portal, que tinha entre seus objetivos a divulgação de assuntos relacionados à cultura japonesa. 
D.T.: Quantos participantes havia inicialmente? Eram descendentes de japoneses em sua maioria?

Oda: Ainda segundo relato de Francisco Handa, das primeiras reuniões participaram apenas os fundadores Roberto Saito, Francisco Handa, Masuda Goga e Koji Sakaguchi, diretor da já citada Revista Portal. Saito (professor) e Handa (monge budista), nisseis. Sr. Sakaguchi, japonês. E Masuda Goga, imigrante japonês naturalizado brasileiro. Depois de algum tempo, poetas brasileiros foram se juntando ao grupo.

D.T.: Eram produzidos somente haikais em português, na época?

Oda: Sim, desde o início. O objetivo principal do Grêmio era o de estudar as possibilidades de produzir haicais em língua portuguesa mantendo o espírito do haicai japonês, com kigo. A essa época, a maioria dos membros era de brasileiros sem ascendência nipônica. Uma ressalva: entre 1987 e 1988, o grupo se dedicou apenas ao estudo dos fundamentos, filosofia, história do haicai etc. As reuniões para criação poética só foram iniciadas em 1989.

D.T.: Onde e com qual frequência acontecem as reuniões do Grêmio Haikai Ipê hoje?

Oda: Atualmente nos reunimos em uma sala cedida por uma associação nipobrasileira, situada à rua Vergueiro, 819, bairro Liberdade. Os encontros são mensais e acontecem sempre no primeiro sábado de cada mês.

D.T.: Como acontecem hoje as reuniões do Grêmio?

Oda: A dinâmica é semelhante à adotada pelos praticantes de língua japonesa e que foi introduzida no Brasil por Nenpuku Sato, de quem Goga foi discípulo. Os temas, ou kigo, dois ou três, são anunciados ao encerramento da reunião do mês anterior. Cada participante deve levar dois haicais, sem identificação de autoria, anotados em pequenos papéis retangulares para apreciação em grupo. Recolhidos os papéis, os haicais são identificados por números e agrupados em bloquinhos. Estes bloquinhos, identificados por letras em ordem alfabética, são distribuídos entre os presentes. Cada participante, após anotar os de sua escolha, deve passar o bloquinho para o colega à esquerda, de modo que, ao término do rodízio, todos os haicais apresentados tenham sido apreciados. As letras apostas no verso do bloquinho servem para controle individual e os números, para lançamento no mapa, na coluna correspondente ao autor. Ao término da leitura e avaliação, o participante deve anotar em uma folha os haicais de sua preferência, datar e assinar. Em geral, escolhemos dez por cento dos trabalhos entregues para avaliação.

Recolhidas as escolhas individuais, que denominamos 'folha de votação', um dos presentes faz a leitura dos haicais, ocasião em que o autor deve se identificar para que os votos sejam registrados em um mapa. Encerrada esta etapa, são 
proclamados os votos obtidos por cada participante, bem como os haicais mais votados. A seguir, a palavra é aberta para o comentário dos presentes e da orientadora, bem como para a justificativa dos autores.

Após breve pausa para um lanche, realizamos a atividade denominada sekidai, isto é, a composição de um haicai em 20 minutos com o tema dado na hora. O processo de avaliação é bem mais simples. Recolhidos os trabalhos, sem identificação de autoria, procede-se à primeira leitura para que os presentes possam tomar conhecimento do todo. Na segunda leitura, as preferências são manifestadas levantando a mão. Os votos obtidos são anotados no próprio papel onde foi apresentado o haicai. Encerrada a leitura, são proclamados os haicais mais votados. A seguir, a orientadora procede à avaliação dos haicais, analisando os textos, um a um, ocasião em que o autor ou qualquer um dos presentes pode fazer uso da palavra para concordar, discordar, acrescentar ou manifestar o seu ponto de vista.

Antes de encerrar a reunião, são anunciados os temas para a reunião seguinte e dadas as informações sobre eventos de interesse do grupo, como palestras, lançamentos de livros, concursos, oficinas literárias, festivais, passeios poéticos. Mas, esse 'modus operandi' não é regra rígida. Se há outros assuntos de interesse do grupo a serem definidos, o sekidai é substituído pela discussão desse assunto.

D.T.: Qual a linha seguida pelo Grêmio na composição dos poemas: Bashô, outros?

Oda: O grêmio Ipê nasceu com o objetivo de estudar as possibilidades de compor o haicai em língua portuguesa, mantendo-se o espírito do haicai japonês. Isto é, composições que tenham o kigo como eixo de sustentação do poema. Esta é a chave dos poemas de Bashô, cujos ensinamentos procuramos seguir.

D.T.: Como se dá a utilização do kigo na composição dos poemas?

Oda: Segundo ensinamentos preconizados pelos grandes mestres, o kigo não pode ser apenas enfeite poético. Muito pelo contrário, deve ser o assunto principal. Então, nós não usamos o kigo para compor o poema. O movimento de criação é inverso: o poema nasce do kigo, que é a alma do haicai. É esse o espírito que buscamos incorporar em nossos textos e que diferencia nossa produção da maioria dos textos publicados no Brasil sob a denominação de haicai.

D.T.: Quantas antologias foram produzidas pelo Grêmio Haicai Ipê desde 2010?

Oda: Apenas uma: “Goga \& Haicai: um sonho brasileiro", em 2011. A antologia teve por objetivo homenagear o mestre no centenário de seu nascimento. Após o seu falecimento em 2008, o grêmio passou por um período de esvaziamento, com a saída de quase todos os veteranos. 
D.T.: Quais as atividades desenvolvidas pelo Grêmio Haicai Ipê além das reuniões?

Oda: Organizamos e coordenamos um concurso denominado Concurso Brasileiro de Haicai Infanto-Juvenil, direcionado a alunos do Ensino Fundamental e Médio. Já se encontram abertas as inscrições para a $16^{\mathrm{a}}$ edição deste concurso.

Também realizamos o Encontro Brasileiro de Haicai, um evento que visa promover a confraternização entre os praticantes de haicai de todo o país.

Em parceria com a Associação Cultural e Literária Nikkei Bungaku do Brasil, realizamos também um concurso anual de haicai denominado Prêmio Masuda Goga.

Promovemos alguns passeios poéticos com o objetivo de manter viva a tradição da composição coletiva in loco. Por exemplo, a contemplação das cerejeiras, a colheita de caquis e mexericas, a festa junina com a tradicional fogueira. Em dezembro, o grêmio promove a confraternização anual (bonenkai). Todas essas atividades acontecem no meu sítio em Caucaia do Alto.

Em parceria com a Nikkei Bungaku, membros do Ipê participam da comissão julgadora do concurso literário Yoshio Takemoto, com quatro modalidades em língua portuguesa.

Membros do Ipê colaboram, também, como jurados do concurso mundial de haicai para crianças promovido pela JAL Foundation, de Tóquio, e copatrocínio da Japan Airlines. Também colaboramos na fundação de novos grêmios, promovemos oficinas e palestras em associações culturais e unidades educacionais.

D.T.: Em quais outras cidades há Grêmios que nasceram do Grêmio Haicai Ipê, atuando? Oda: Ativos, temos apenas em Santos, no Rio de Janeiro, em Magé e em Irati. Os de Manaus, Brasília, Recife, Curitiba, Bandeirantes e Cornélio Procópio se encontram inativos.

D.T.: Em seu livro "Furusato no Uta - canção da terra natal" você conta de sua forte relação com a natureza. Essa relação é imprescindível para que uma pessoa escreva haikais?

Oda: Com certeza. Diferente da poesia lírica que nasce de dentro para fora, cujo conteúdo é subjetivo e intimista, haicai é poesia que nasce de fora para dentro, é um canto em louvor à Natureza. Sol, lua, flores, pássaros, insetos, elementos que nos rodeiam, são a fonte de inspiração do haicaísta. Mas a natureza se transforma a cada dia, a cada estação. Nada é estático. Nada é definitivo. Tudo é transitório. Então, sem um estreito relacionamento, sem uma vivência cotidiana, impossível penetrar sua alma, conhecer suas particularidades. E o haicai é exatamente isso: poesia que emana de um fugaz aqui e agora. 
D.T.: Em algumas entrevistas você fala do papel do haikai como instrumento de mudança do comportamento humano. Como se dá a intervenção da poesia e essa mudança?

Oda: A mudança de comportamento não decorre da poesia em si, mas da atitude que embasa o ato de compor o haicai. Por trás desse pequeno texto há uma filosofia milenar que lhe dá sustentação. Despojamento, negação do ego, valorização do essencial, gratidão, amor e respeito à natureza são alguns dos princípios que norteiam ou agregam sabor ao pequeno poema. Acontece que para que os seus poemas tenham essas características, primeiro, é preciso que você as tenha. Haicai é um canto em louvor à natureza. Para que seu haicai reflita isso, é preciso que você seja fonte de amor. Você não pode dar o que não tem, não é mesmo? Então, haicai é atitude. É um jeito de ser e de estar no mundo.

D.T.: Quais as suas expectativas quanto ao futuro do Grêmio Haicai Ipê?

Oda: Quero muito que novas lideranças surjam para dar continuidade ao trabalho iniciado por meu mestre. Mas, talvez por minha própria incompetência, não estou conseguindo sensibilizar ninguém para assumir a tarefa; então, não sei prever o futuro do Grêmio, não alimento muitas expectativas. Mas, como diz o provérbio "enquanto houver vida, há esperança".

D.T.: Quais são os seus planos para os próximos cinco anos?

Oda: Na verdade, não faço muitos planos para o futuro. Eu vivo o presente. Mas, se o Deus da Vida me permitir viver mais 5 anos, e houver candidatos, gostaria muito de ajudá-los a dar continuidade aos sonhos de mestre Goga, que era fazer do Brasil a segunda pátria do haicai. 